\title{
Efficient anionic surfactant treatment of cork for cationic dye removal from aqueous media
}

\author{
Azizi A. ${ }^{1}$, Krika F. ${ }^{2 *}$ and Krika A. ${ }^{3}$ \\ ${ }^{1}$ Department of The Common Trunk Sciences and Technology, Faculty of Technology, University of Laghouat, Highway Ghardaia BP G37 \\ (M'kam) 03000, Laghouat, Algeria \\ 2University of Mohamed Seddik Ben Yahia, LIME Laboratory, Faculty of Sciences and Technology, BP 98 Ouled Aissa, Jijel, 18000, Algeria \\ ${ }^{3}$ Department of Environmental Sciences and Agronomic Sciences, Faculty of Nature Life and Sciences, University of Jijel, BP 98 Ouled \\ Aissa, Jijel 18000, Algeria \\ Received: 05/05/2021, Accepted: 23/05/2021, Available online: 07/06/2021 \\ *to whom all correspondence should be addressed: e-mail: f.krika@hotmail.fr \\ https://doi.org/10.30955/gni.003702
}

\section{Graphical abstract}

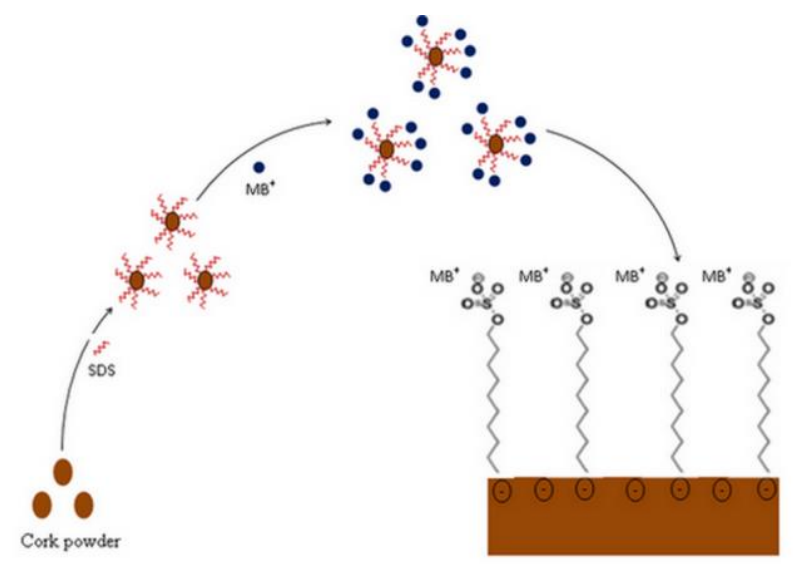

\section{Abstract}

Sodium dodecyl sulfate modified Algerian cork powder (SDS-ACP) with interesting biosorption capacity was prepared for dye removal from aqueous media. The decolorization performance of SDS-ACP was studied using methylene blue (MB) as a model dye. Experiments were conducted in batch system. The effects of initial $\mathrm{pH}$, biosorbent dose, dye concentration, contact time and temperature were investigated. The kinetic modelling study showed that the experimental data are perfectly adjustable to the pseudo-second order model, with regression coefficients close to the unity and the intraparticle diffusion is not only the key controlling-step in the biosorption process. Langmuir isotherm was the most suitable model for describing the biosorption equilibrium results, which confirm the monolayer coverage and the maximum biosorption uptake of SDS-ACP was $117 \mathrm{mg} . \mathrm{g}^{-1}$. Thermodynamic parameters such as Gibbs free energy, entropy and enthalpy were also evaluated showing that the biosorption process was spontaneously feasible and exothermic in nature. The application treatment has shown that SDS-ACP is a suitable lignocellulosic-type biosorbent for the decolorization of MB-colored solutions

Keywords: biosorption, MB, SDS-ACP, thermodynamics

\section{Introduction}

Dyes come into the environment through effluent streams from the textile, dyeing, pulp tannery, and paint industries which can cause the pollution of the environment. They are dangerous to aquatic life and humans and their elimination is of considerable significance (Elemen et al., 2012). Various methods such as coagulation/flocculation (Verma et al., 2012), membrane separation (Chidambaram et al., 2015), ion exchange (Greluk et al., 2015), chemical oxidation (Turgay et al., 2011), electrochemical method (Singh et al., 2013), photodegradation (Duta et al., 2015) and biological degradation (Kanagaraj et al., 2015), have been considered in order to eliminate dyes from wastewater.

Biosorption appears to be a very efficient, economical and extensively used process for the treatment of colored wastewaters. It is considered as a promising substitute to conventional costly technologies. The biosorption method is based on biomass - pollutant interactions resulting in the elimination of organic and / or inorganic contaminants by dead biomasses (Lu et al., 2011). Of the diverse kinds of biosorbent materials, lignocellulosic biomasses as industrial wastes have been more used in biosorption processes with a good removal potentiel and low or no cost. Cotton stalk (Deng et al., 2011), rice husk (Safa et al., 2011), sugarcane bagass ash (Kanawade and Gaikwad, 2011) are few examples of recent research related to lignocellulosic biosorbent materials. Moreover, to efforts associated to preparation of the lignocellulosic-type biosorbent materials, surface modifications by various agents have been investigated for the enhancement of the sorption potential of biomaterials (Abdolali et al., 2014; Chakraborty et al., 2011; Nguyen et al., 2014). In the current investigation, modified biosorbent was prepared from waste biomass of the manufacturing process of cork waterproof panels. The natural form of cork biomass has 
already been used for the removal of dye and heavy metal such as $\mathrm{Cd}, \mathrm{Cu}, \mathrm{Zn}$, Methyl orange and Methylene Blue (Krika et al., 2016; krika and benlahbib, 2015; Chubar et al., 2004). On the other hand, modified cork has not been used yet to remove dyes from colored wastewater. Sodium dodecyl sulfate (SDS) was used for the first time for the chemical modification of this biomass and the developed biomaterial was employed for decolorization.

Methylene blue (MB) was chosen in this study as a model cationic dye. The most important operating parameters such as $\mathrm{pH}$, biosorbant mass, initial dye concentration, contact time and temperature have been investigated. The experimental results were analysed to study the equilibrium, thermodynamic aspect of the biosorption and to assess the biosorption performance of the developed biosorbent.

\section{Materials and methods}

\subsection{Chemicals}

All reagents used (Methylene blue, $\mathrm{CH}_{3}\left(\mathrm{CH}_{2}\right)_{11} \mathrm{SO}_{4} \mathrm{Na}$, $\mathrm{H}_{2} \mathrm{SO}_{4}, \mathrm{NaOH}$ ) were of analytical grade (Sigma-Aldrich). The $\mathrm{MB}$ (Figure.1) stock solution was prepared by dissolving the appropriate quantity in distilled water. The initial solution $\mathrm{pH}^{\prime} \mathrm{s}$ was adjusted with dilute sulfuric acid $(0.1 \mathrm{~N})$ and sodium hydroxide $(0.1 \mathrm{~N})$.<smiles>CN(C)c1ccc2nc3ccc(N(C)C)cc3[s+]c2c1</smiles>

Figure 1. MB structure

\subsection{Biosorbent modification}

The biosorbent used was kindly supplied by the Algerian company-EPE/JIJEL Etancheite's SPA. It has been prepared according to the method described by Krika et al. (2015). Experiments were performed with a size fraction with a particle diameter $d<0.16 \mathrm{~mm}$. The ACP was treated with $1 \%$ (w/v) surfactant (SDS) solution, stirred at $50{ }^{\circ} \mathrm{C}$ for $4 \mathrm{~h}$. The SDS-ACP was filtered, washed several times with osmosis water to remove dissolved impurities and residual surfactant, dried in an oven at $60^{\circ} \mathrm{C}$ for $24 \mathrm{~h}$ and then stored in desiccators to be used.

\subsection{Surface studies}

The $p H_{p z c}$ ( $p H$ of zero point of charge) value was determined by adding a quantity of modified cork $(0.15 \mathrm{~g})$ to a series of bottles containing $50 \mathrm{~mL}$ of $\mathrm{NaOH}(0.01 \mathrm{~N})$. Previous to adding the biosorbent, the $\mathrm{pH}$ was adjusted to initial values ranged from 2 to 10 by adding of either $0.1 \mathrm{~N}$ $\mathrm{H}_{2} \mathrm{SO}_{4}$ or $0.1 \mathrm{~N} \mathrm{NaOH}$. The suspensions were stirred for 48 $\mathrm{h}$ and final $\mathrm{pH}$ values were measured. The point of intersection of the curve $\left(\mathrm{pH}_{\mathrm{i}}-\mathrm{pH}\right)=\mathrm{f}\left(\mathrm{pH}_{\mathrm{i}}\right)$ is the point of zero charge of the biosorbent surface (Balistrieri and Murray, 1981).The surface of cork after treatment as well as after dye biosorption were characterized by Fourier transform infrared (FT-IR) analysis in the range of 400-4000 $\mathrm{cm}^{-1}$ (FTIR spectrometer Tensor II, Bruker).

\subsection{Dye biosorption experiments}

The biosorption studies were carried out in batch mode. A known amount of biosorbent was introduced in flasks containing certain concentration of $\mathrm{MB}$. The mixture was stirred during a determined time. While equilibrium was reached, the absorbance of supernatants was determined by spectrophotometer (Shimadzu UV-vis 1240) at the maximum absorbency visible wavelength $\left(\lambda_{\max }=664 \mathrm{~nm}\right)$.

The uptake of biosorbed dye per unit mass of biosorbent at equilibrium, $q_{e}\left(\mathrm{mg} \mathrm{g}^{-1}\right)$, and the biosorption percentage, (\% removal), were calculated using the following relationships:

$$
\begin{aligned}
& q_{\mathrm{e}}=\frac{\left(C_{0}-C_{\mathrm{e}}\right) \cdot V}{m} \\
& \text { \%removal }=\frac{\left(C_{0}-C_{\mathrm{e}}\right)}{C_{0}} \cdot 100
\end{aligned}
$$

Where $V$ is the volume of the solution (L), $m$ is the mass of biosorbent $(\mathrm{g}), C_{0}$ is the initial $\mathrm{MB}$ concentration $\left(\mathrm{mg} \mathrm{L}^{-1}\right), C_{\mathrm{e}}$ is the $\mathrm{MB}$ equilibrium concentration $\left(\mathrm{mg} \mathrm{L}^{-1}\right)$ in liquid phase and $q_{\mathrm{e}}$ is the dye quantity biosorbed at equilibrium (mg g $\left.{ }^{1}\right)$.

\section{Results and discussion}

\subsection{Surface studies}

In order to understand the MB biosorption process, FTIR spectroscopy was used to analyse characteristic functional groups of SDS-ACP before and after MB loaded (Figure 2(A) and (B)).

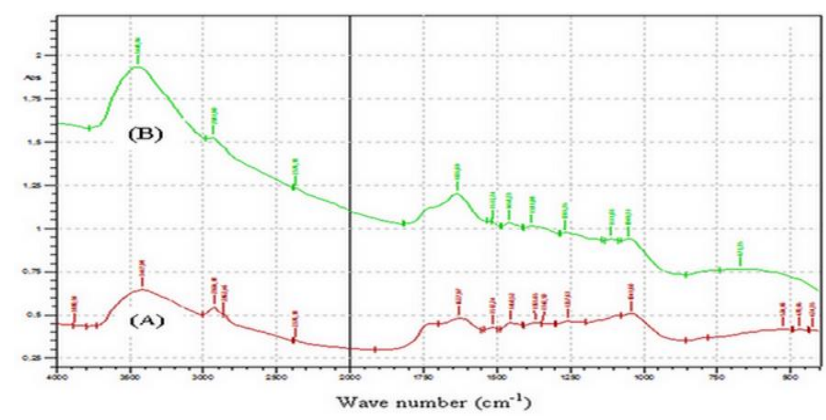

Figure 2. FTIR spectra of SDS-ACP: (A) before MB biosprtion, (B) after $\mathrm{MB}$ biosorption

The broad absorption band at $3417.98 \mathrm{~cm}^{-1}$ representing the O-H stretching vibration of alcohols, phenols and carboxylic acids (Liang et al., 2010). The additional bands at about 2924.18, 2862.48, 1627.97, 1450.52 and 1041.60 $\mathrm{cm}^{-1}$ corresponding to $-\mathrm{CH}_{2},-\mathrm{C}-\mathrm{H}, \mathrm{C}-\mathrm{C}, \mathrm{C}=\mathrm{O}$, and $\mathrm{C}-\mathrm{O}$, respectively.

On the other hand, the biosorbent MB loaded spectra revealed small modifications in absorption band frequencies. The absorption peaks at 3417.98, 2924.18, 1627.97, and $1041.60 \mathrm{~cm}^{-1}$ (Figure 2(A)) had shifted, to $3448.84,2931.90,1635.69$, and $1049.31 \mathrm{~cm}^{-1}$, respectively (Figure 2(B)). This shift in the absorption band frequencies 
recommended the interactions of $\mathrm{MB}$ molecules with the functional groups of SDS-ACP (Liang et al., 2010).

\subsection{Effect of $p H$}

The $\mathrm{pH}$ of aqueous media apply a great impact on the biosorption removal of dyes probably due to its influence either on the surface binding-sites of the biosorbent and in the ionization system of the dye molecules (Ncibi et al., 2009).

To explore the effect of $\mathrm{pH}$ on $\mathrm{MB}$ removal onto SDS-ACP, solution's $\mathrm{pH}$ was varied from 2 to 8 for an initial $\mathrm{MB}$ concentration of $100 \mathrm{mg} \mathrm{L}^{-1}$ and biosorbent mass of $20 \mathrm{mg}$ $\mathrm{L}^{-1}$. The result was presented in Figure 3 .

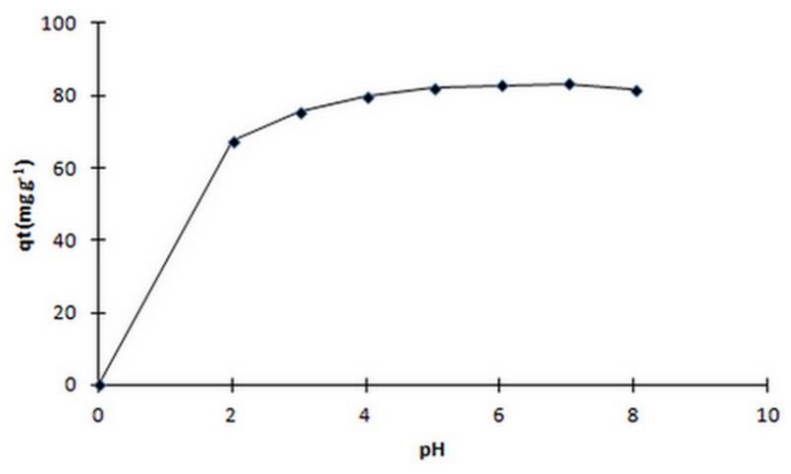

Figure 3. $\mathrm{pH}$ effect on $\mathrm{MB}$ biosorption onto SDS-ACP ( $\mathrm{CO}=100 \mathrm{mg} \mathrm{L}^{-1}, \mathrm{~m}=20 \mathrm{mg}$, Contact time $=120 \mathrm{~min}$, Stirring speed $=250 \mathrm{rpm}, T=25^{\circ} \mathrm{C}$ ).

At $\mathrm{pH}=4$, the removal uptake of SDS-ACP was $79.7 \mathrm{mg} \mathrm{g}^{-1}$ and there is no important variation in the residual $M B$ concentration over the initial $\mathrm{pH}$ ranges of 5-8. At low $\mathrm{pH}$ values, the $\mathrm{H}^{+}$concentration is high, which competes with $\mathrm{MB}$ ions for surface active sites. Conversely, the SDS-ACP shows higher elimination performance, indicating that the surfactant has played an important role in the biosorption process.

The point of zero charge (PZC) can be utilized else to clarify the effect of $\mathrm{pH}$ on $\mathrm{MB}$ biosorption. At $\mathrm{pH}=\mathrm{PZC}$, the surface charge of the bisorbents is neutral; the electrostatic attraction existing among the surface of the biosorbent and the $\mathrm{MB}$ cations in aqueous media is not significant. When $\mathrm{pH}>$ or $\angle \mathrm{PZC}$, the equilibrium is busted. At $\mathrm{pH}<\mathrm{PZC}$, the surface of the biosorbents is positively charged, who inhibits the approach of the positive charges of MB ions. At $\mathrm{pH}>\mathrm{PZC}$, the surface of the biosorbents is negatively charged and the functional groups like carboxyl and hydroxyl groups are free to interact with the MB cations. Maximum biosorption can occur at $\mathrm{pH}$ values above PZC when the biosorbents surface has a negative charge (Romero-Gonzalez et al., 2001). The law of PZC agrees with biosorption performance of biosorbents (Lihua et al., 2011). The PZC of SDS-ACP is 3.20 (Figure 4). Hence, SDS$\mathrm{ACP}$ has a great biosorption capacity at a lower $\mathrm{pH}$ range. These results are in agreement with our results, as presented in Figure 3.

By considering the combination of $\mathrm{PZC}$ value and the impact of $\mathrm{pH}$ on $\mathrm{MB}$ biosorption investigation, the following mechanism (Figure 5) could be considered: The driving force of the MB biosorption must be the Coulomb (electrostatic) attraction.

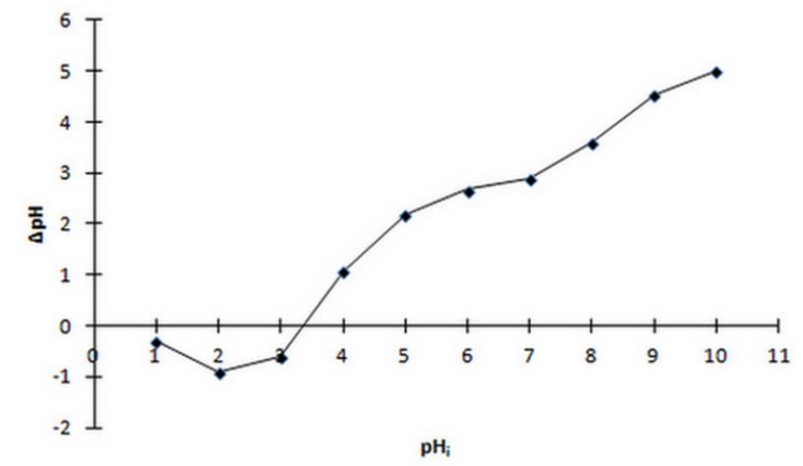

Figure 4. Determination of $\mathrm{pH}_{\mathrm{PZC}}$ of SDS-ACP.

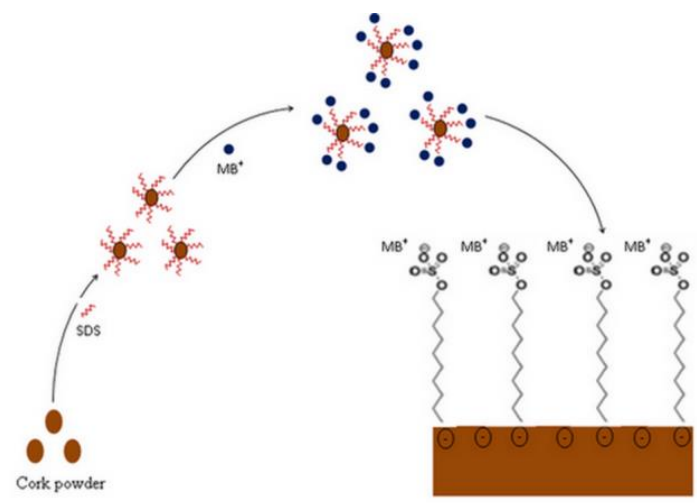

Figure 5. Illustration of the functionalization of SDS-ACP and the suggested mechanism for MB biosorption.

\subsection{Effect of biosorbent masse on $M B$ biosorption}

So as to assess the influence of the SDS-ACP mass on MB removal, several quantities of the biosorbent varying from $10 \mathrm{mg}$ to70 $\mathrm{mg}$ were used, and biosorption of $\mathrm{MB}$ was reached at $298 \mathrm{~K}$. Figure 6 shows the removal rate of $\mathrm{MB}$ onto SDS-ACP. The results reveal that the removal yield is positively related with the quantity of biosorbent added. A fast removal percentage increases with the addition of SDSACP when the mass is below of $20 \mathrm{mg}$, after that it increases slowly. This tendency may be as the result of the increase number of binding sites with the augmentation in the biosorbent amount.

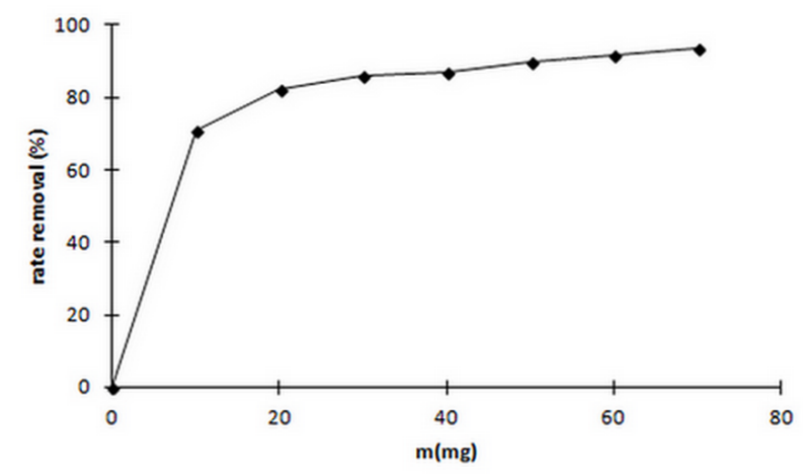

Figure 6. Effect of biosorbent masse on $\mathrm{MB}$ removal SDS-ACP $\left(\mathrm{C}_{0}=100 \mathrm{mg} \mathrm{L}^{-1}, \mathrm{pH}=6\right.$; Contact time $=120 \mathrm{~min}$; Stirring speed $=$ $250 \mathrm{rpm} ; T=25^{\circ} \mathrm{C}$ ). 
The maximum rate removal of SDS-ACP increased from $70.70 \%$ to $93.30 \%$ with rising biosorbent dosage from 10 $\mathrm{mg}$ to $70 \mathrm{mg}$. Thus, $40 \mathrm{mg}$ of SDS-ACP was chosen as the suitable biosorbent dose in $\mathrm{MB}$ removal investigation

\subsection{Effect of contact time and biosorption kinetics}

The contact time was also evaluated as an important factor of the adsorption efficiency (Lihua et al., 2011). Figure 7 shown the impacts of contact time on $M B$ removal onto SDS-ACP.

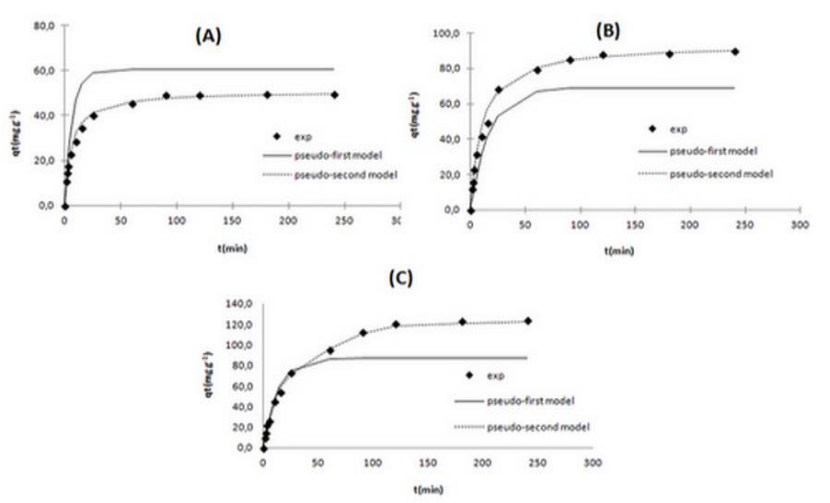

Figure 7. Effect of contact time on $\mathrm{MB}$ removal and biosorption kinetics ont SDS-ACP: (A) $100 \mathrm{mg} \mathrm{L}^{-1}$, (B) $200 \mathrm{mg} \mathrm{L}^{-1}$ and (C) 300 $\mathrm{mg} \mathrm{L}^{-1}\left(\mathrm{~m}=40 \mathrm{mg}, \mathrm{pH}=6\right.$; Stirring speed $\left.=250 \mathrm{rpm} ; T=25^{\circ} \mathrm{C}\right)$.

It is clearly visible that the biosorption rate of $\mathrm{MB}$ increases rapidly with increasing contact time prior to $30 \mathrm{~min}$, then slows down with increasing contact time until equilibrium is reached. At high MB concentration a significant driving force exist to conquer all resistances of the dye among the aqueous and solid phases, thus increasing the removal (Slimani et al., 2014).

The fitting as a function of time of $M B$ biosorption to pseudo-first (Lagergren, 1898), pseudo-second (Ho and McKay, 1999) and Weber-Moris (1963) models (equations 3-5) are presented in Table 1 and nonlinear adjustement has been carried out to establish the model parameters:

$$
\begin{aligned}
& \text { Pseudo-first } q_{\mathrm{t}}=q_{\mathrm{e}}\left(1-e^{k_{1} t}\right) \\
& \text { Pseudo-second } \frac{t}{q_{\mathrm{t}}}=\frac{1}{k_{2} q_{\mathrm{e}} 2}+\frac{t}{q_{\mathrm{e}}} \\
& \text { Weber-Moris } Q_{\mathrm{t}}=k_{\mathrm{id}} t^{0.5}
\end{aligned}
$$

Where $q_{t}$ and $q_{\mathrm{e}}$ are the amount of MB biosorbed $\left(\mathrm{mg} \mathrm{g}^{-1}\right)$ at time $t$ ( $\mathrm{min}$ ) and equilibrium, $k_{1}$ is the pseudo first-order rate constant $\left(\mathrm{min}^{-1}\right), \mathrm{k}_{2}$ is the pseudo second order rate constant (g. (mg. $\left.\mathrm{min}^{-1}\right)$ and $k_{\text {id }}$ is the intraparticle diffusion coefficient.

From Table 1, the pseudo-second order kinetic pattern provides far exceed $R^{2}$ values $(0.999,0.999$ and 0.997$)$ than those of the pseudo first kinetic model $(0.958,0.930$ and 0.973 ), showing that the pseudo-second-order model was the most appropriate fit to describe experimental kinetic results. The nonlinear kinetics models were favored than linear models, as the last does not take into consideration the errors related to every experimental data, that cannot

\begin{tabular}{|c|c|c|c|c|c|c|}
\hline \multirow{3}{*}{ MB concentration (mg L-1) } & \multicolumn{3}{|c|}{ Pseudo-first order } & \multicolumn{3}{|c|}{ Pseudo-second order } \\
\hline & \multicolumn{2}{|r|}{$q_{\mathrm{e}}$} & \multirow{2}{*}{$\begin{array}{c}k_{1} \\
\left(\mathrm{~min}^{-1}\right)\end{array}$} & \multicolumn{2}{|r|}{$q_{\mathrm{e}}$} & \multirow{2}{*}{$\begin{array}{c}k_{2} \\
g(m g ~ m i n)^{-1}\end{array}$} \\
\hline & $R^{2}$ & $\left(\mathrm{mg} \mathrm{g}^{-1}\right)$ & & $R^{2}$ & $\left(\mathrm{mg} \mathrm{g}^{-1}\right)$ & \\
\hline 100 & 0.958 & 60.30 & 0,1516 & 0.999 & 48.46 & 0.00339 \\
\hline 200 & 0.930 & 69.00 & 0,0592 & 0.999 & 86.62 & 0.00107 \\
\hline 300 & 0.973 & 87.30 & 0,0769 & 0.997 & 119.90 & 0.00040 \\
\hline
\end{tabular}
regularly be linearized (Vaghetti et al., 2008).

Table 1. Pseudo-first order and pseudo second order kinetic models for the biosorption of MB on SDS-ACP

Table 2. Langmuir and Freundlich constants for biosorption of MB onto SDS-ACP

\begin{tabular}{ccccccc}
\hline \multirow{2}{*}{ Temperature (K) } & \multicolumn{3}{c}{ Langmuir } & \multicolumn{3}{c}{ Freundlich } \\
\cline { 2 - 7 } & $\boldsymbol{q}_{\mathbf{m}}\left(\mathbf{m g ~ g}^{-1}\right)$ & $\boldsymbol{K}_{\mathbf{L}}\left(\mathbf{L ~ m g}^{-1}\right)$ & $\boldsymbol{R}^{\mathbf{2}}$ & $\boldsymbol{K}_{\mathbf{F}}$ & $\boldsymbol{n}$ & $\boldsymbol{R}^{\mathbf{2}}$ \\
\hline 298 & 117.0 & 0.194 & 0.999 & 19.52 & 2.69 & 0.819 \\
\hline 308 & 101.1 & 0.065 & 0.998 & 9.97 & 2.22 & 0.843 \\
\hline 318 & 93.38 & 0.021 & 0.999 & 4.61 & 1.79 & 0.889 \\
\hline
\end{tabular}

The pseudo-second-order model characterizes phenomena at the particle/aqueous media interface, and often illustrate biphasic kinetics with a rapid removal at the beginning, after that with a slower removal. Consequently, the results are described by two stages pseudo-second order model behavior, which can be explained as reactions on two kinds of sites: quickly accessible external sites and less accessible internal sites (Sparks, 1999). Our results are in agreement with this behavior. At the initial rapid removal phase, the biosorption rate of $\mathrm{MB}$ increases quickly with the raise of contact time prior $30 \mathrm{~min}$ because of the fast binding of the cell surface with MB. At the latter biosorption phase, the removal process supposes that the elimination of $\mathrm{MB}$ by the SDS-ACP was possibly not only due to cell-surface binding, but to intra particle diffusion (Bajpai et al., 2007). This possible behavior is examined using the Weber-Morris model. The plot of $q_{t}$ against $t^{0.5}$ should be straight line when biosorption mechanism follows the intra particle diffusion process, and if these lines pass through the origin, the intraparticle diffusion is the ratelimiting step. The plots of $q_{t}$ versus $t^{0.5}$ are presented in Figure 8.

It is clear that these plots do not pass via the origin, signifying that the intraparticle diffusion is not the single rate-controlling step, but also some of degree of boundary layer control like a very slow rate of migration 
of adsorbate from the liquid phase on to the adsorbent surface (Hameed, 2008; Doğan et al., 2007).
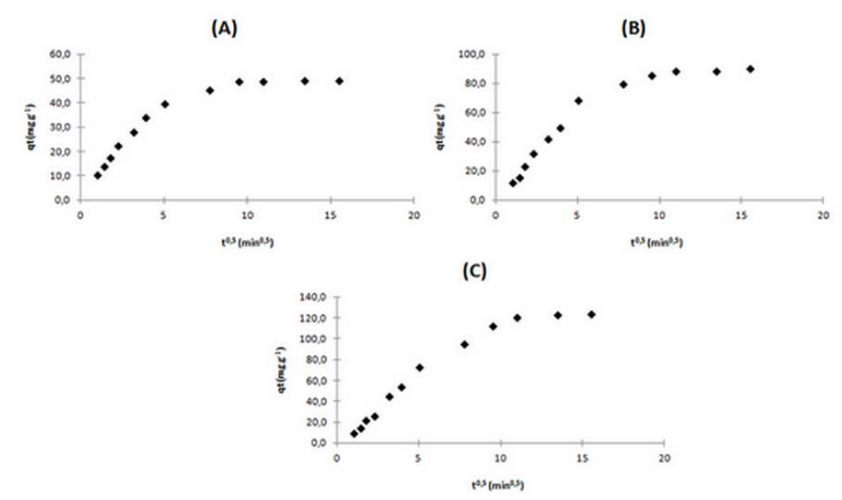

Figure 8. Intraparticle diffusion plot of $\mathrm{MB}$ biosorption onto SDS-ACP: (A) $100 \mathrm{mg} \mathrm{L}^{-1}$, (B) $200 \mathrm{mg} \mathrm{L}^{-1}$ and (C) $300 \mathrm{mg} \mathrm{L}^{-1}(\mathrm{~m}=$ $40 \mathrm{mg}, \mathrm{pH}=6$; Stirring speed $=250 \mathrm{rpm} ; T=25^{\circ} \mathrm{C}$ )

\subsection{Biosorption isotherms}

In this section, the relationships among the initial $M B$ concentration and the biosorbed quantity of $\mathrm{MB}$ onto SDS-ACP are investigated. Langmuir and Freundlich isotherms are the most used in the modelling of dyes biosorption onto biomass. Langmuir isotherm is represented by the following equation (Langmuir, 1918):

$$
q_{\mathrm{e}}=\frac{q_{\mathrm{m}} K_{\mathrm{L}} C_{\mathrm{e}}}{1+K_{\mathrm{L}} C_{\mathrm{e}}}
$$

Freundlich isotherm model can be described by the following equation (Freundlich, 1906):

$$
q_{\mathrm{e}}=K_{\mathrm{F}} C_{\mathrm{e}}^{1 / n}
$$

Where $q_{e}$ : equilibrium biosorption capacity $\left(\mathrm{mg} \mathrm{g}^{-1}\right), C_{e}$ the equilibrium concentration of the solute in the liquid phase ( $\mathrm{mg} \mathrm{L}^{-1}$ ), $q_{m}$ : maximum bisorption capacity ( $\mathrm{mg} \mathrm{g}^{-}$ $\left.{ }^{1}\right) ; K_{L}$ : Langmuir constant representing the biorption energy parameter, $K_{F}$ is the sorption capacity constant and $n$ the Freundlich constant for surface heterogeneity.

The adjustments of the experimental data are presented in Figure 9 and the model parameters are listed in Table 2.

These curves (Figure 9) show that the MB amount increases with increasing the equilibrium concentration of $\mathrm{MB}$ after that, a plateau is reached. It is attributed to the saturated active sites of the SDS-ACP surface.

From Table 2, The $R^{2}$ values of the Langmuir isotherms are $0.999,0.998$ and 0.999 for the biosorption of $\mathrm{MB}$ onto SDS-ACP at the studied temperature, respectively, greater than that of the Freundlich isotherms $(0.819$, 0.843 and 0.889 ), indicating that the Langmuir model was more appropriate for describing MB biosorption equilibrium results using modified cork biomass at the studied temperature interval. In other words, the removal of $\mathrm{MB}$ onto SDS-ACP was occurred at the binding sites on the biosorbent surface as a monolayer biosorption. In addition, the parameters of the Langmuir model can be utilized to predict the affinity biosorbent/sorbate using the dimensionless separation factor $\left(R_{L}\right)$, defined as:

$$
R_{\mathrm{L}}=\frac{1}{1+K_{\mathrm{L}} C_{0}}
$$

The $R L$ value may be utilized to predict if a removal process is "favorable" or "unfavorable". (Cengiz et al., 2012). If the $R_{L}$ values are in the range of 0 and 1 , it shows a favorable biosorption. The values of $R_{L}$ for the $\mathrm{MB}$ biosorption on SDS-ACP are shown in Figure 10. All values of our experimental data are between 0 and 1 at all initial $M B$ concentrations, signifying that the $M B$ removal by SDS-ACP was a favorable system.

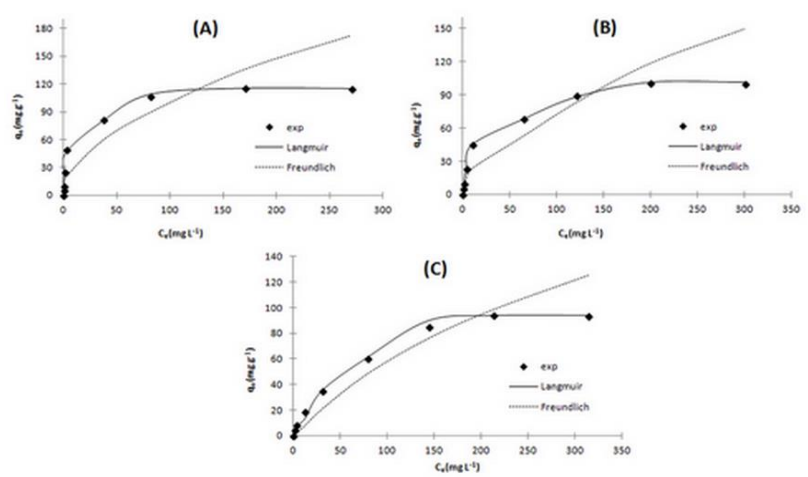

Figure 9. Langmuir and Freundlich biosorption isotherms of MB onto SDS-ACP: (A) $25^{\circ} \mathrm{C}$, (B) $35^{\circ} \mathrm{C}$ and (C) $45^{\circ} \mathrm{C}(\mathrm{m}=40 \mathrm{mg}$, $\mathrm{pH}=6$; Stirring speed $=250 \mathrm{rpm}$ )

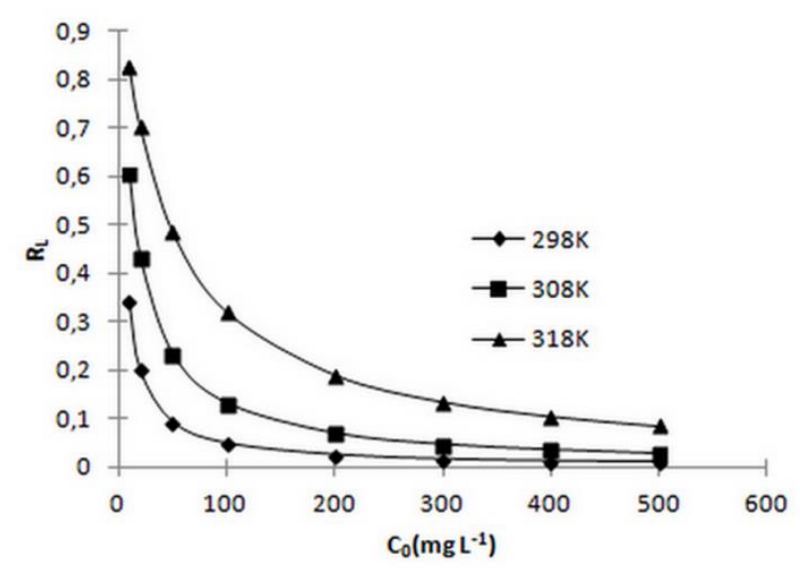

Figure 10. Values of RL for the biosorption of MB by SDS-ACP

Based on the Langmuir pattern, the maximum SDS-ACP capacity for $\mathrm{MB}$ removal was $117 \mathrm{mg} \mathrm{g}^{-1}$. In the removal process of MB onto SDS-ACP, $q_{m}$ and $K_{L}$ values decreased with increasing in the solution temperature. The values of $q_{m}$ decreased from 117 to $93.38 \mathrm{mg} \mathrm{g}^{-1}$, as temperature increased from 298 to $318 \mathrm{~K}$. The same tendency was observed for $K_{L}$ values. The decrease of $q_{m}$ and $K_{L}$ values with rise in solution temperature indicates that the biosorption of $\mathrm{MB}$ on modified cork are favorable at lower temperatures. i.e; the MB biosorption is an exothermic process.

To exhibit the good biosorption ability of MB onto SDS$A C P$, an exhaustive comparison with other sorbent materials was conducted. Table 3 illustrates that, with a 
sorption capacity of about $117 \mathrm{mg} \mathrm{g}^{-1}$, the SDS-ACP is a promising high performance biomaterial. Thereby, cheap, available, and capable to be regenerated.
Surfactant modified cork appear as very competitive to other MB-biomaterials.

Table 3. Maximum biosorption capacities of MB from aqueous media using different various biosorbents

\begin{tabular}{|c|c|c|}
\hline Adsorbents & $q_{m}\left(\mathrm{mg} \mathrm{g}^{-1}\right)$ & References \\
\hline Modified Algerian cork & 117 & This study \\
\hline Activated biochar & 77.35 & Zhong et al. (2018) \\
\hline Modified biochar & 503 & Que et al. (2018) \\
\hline Cherry sawdust & 39.84 & Ferrero (2007) \\
\hline Spent rice biomass & 8.3 & Rehman et al. (2012) \\
\hline Neem leaf powder & 3.67 & Bhattacharyya and Sharma (2005) \\
\hline Coffee husk & 90.1 & Oliveira et al. (2008) \\
\hline Citrus sinensis Bagasse & 96.4 & Bhatti et al. (2012) \\
\hline
\end{tabular}

Table 4. Thermodynamic parameters of biosorption of MB on SDS-ACP

\begin{tabular}{ccccc}
\hline $\mathrm{T}(\mathrm{K})$ & $\Delta \boldsymbol{G}^{0}\left(\mathrm{~kJ} \mathrm{~mol}^{-1}\right)$ & $\Delta \boldsymbol{S}^{0}\left(\mathrm{~J} \mathrm{~mol} \mathbf{~ m}^{-1} \mathrm{~K}^{-1}\right)$ & $\Delta H^{0}\left(\mathrm{~kJ} \mathrm{~mol}^{-1}\right)$ & $\mathbf{R}^{\mathbf{2}}$ \\
\hline 298 & -20.67 & & & \\
\hline 308 & -21.01 & 33.52 & -10.69 & 0.998 \\
\hline 318 & -21.34 & & & \\
\hline
\end{tabular}

\subsection{Thermodynamic analysis}

The thermodynamic parameters that make it easy for us to identify the nature of the removal of $\mathrm{MB}$ on modified cork are standard free energy change $\left(\Delta G^{\circ}\right)$, standard enthalpy $\left(\Delta H^{\circ}\right)$ and standard entropy $\left(\Delta S^{\circ}\right)$ were determined using the following equations:

$$
\begin{aligned}
& K_{\mathrm{d}}=\frac{q_{\mathrm{e}}}{C_{\mathrm{e}}} \\
& \Delta G^{0}=-R T \ln K_{\mathrm{d}} \\
& \ln K_{\mathrm{d}}=\left(\frac{\Delta S^{0}}{R}\right)-\left(\frac{\Delta H^{0}}{R}\right) \cdot \frac{1}{T}
\end{aligned}
$$

Where $K_{d}$ : distribution constant; $R$ : perfect gas constant $(J$ $\left.\mathrm{mol}^{-1} \mathrm{~K}^{-1}\right) ; T$ : absolute temperature $(K)$.

A plot of In $K_{d}$ against $1 / T$ (data not shown) yields a straight line and $\Delta H^{\circ}, \Delta S^{\circ}$ and $\Delta G^{\circ}$ values are presented in Table 4.

The negative value of $\Delta H^{\circ}$ confirms the exothermic of the $\mathrm{MB}$ biosorption process. Besides, the magnitude of $\Delta H^{\circ}$ gives information regarding to the kind of biosorption, which can be either physical or chemical. A $\Delta H^{\circ}$ varied from 2.1 to $20.9 \mathrm{~kJ} \mathrm{~mol}^{-1}$ corresponds to a physical biosorption (Anayurt et al., 2009). The value obtained of $\Delta H^{\circ}$ is in the interval of physisorption, hence, the $\mathrm{MB}$ biosorption on modified cork is occured through a physisorption. The positive value of change entropy $\left(\Delta S^{\circ}\right)$ shows the affinity of SDS-ACP for MB; the association of the adsorbate at the solid-solution interface becomes more random. The reaction is feasible and spontaneous, as $\Delta G^{\circ}$ values are negative at studied temperatures. Usually, $\Delta G^{\circ}$ values vary between 0 and $-20 \mathrm{~kJ} \mathrm{~mol}^{-1}$ for physical biosorption but chemisorption is in a range of -80 to $-400 \mathrm{~kJ} \mathrm{~mol}^{-1}$ (Jaycock and Parfitt, 1981). In this study, the values of $\Delta G^{\circ}$ obtained are within the ranges of -20 and $0 \mathrm{~kJ} \mathrm{~mol}^{-1}$, which indicate that the physisorption is the main dominant mechanism.

\section{Conclusion}

This investigation studied the biosorption of methylene blue from aqueous media using chemically surface modified Algerian cork. The following conclusions can be drawn:

- The biosorption process was found to be not strongly $\mathrm{pH}$ influenced

$-\mathrm{MB}$ biosorption increased with increasing biosorbent dosage, contact time, initial MB concentration while it decreased with increasing temperature.

- The pseudo-second order was the most suitable pattern to describe kinetic data

- The biosorption of MB was not only controlled by the intra-particle diffusion

- The experimental results were well fitted with the Langmuir isothermal model at the studied temperatures, indicating maximum capacity of $117 \mathrm{mg} \mathrm{g}^{-1}$.

- Thermodynamic analysis showed that the MB removal onto SDS-ACP was spontaneous and exothermic under studied conditions.

- Thermodynamic analysis showed that the MB removal on biosorbent was spontaneous and exothermic under studied conditions.

In conclusion, surfactant-surface modified cork was verified to be a useful and an alternative biosorbent, as compared to biosorbents reported in bibliography, for $\mathrm{MB}$ removal from aqueous solution. 


\section{References}

Abdolali A., Guo W.S., Ngo H.H., Chen S.S., Nguyen N.C. and Tung K.L. (2014), Typical lignocellulosic wastes and by-products for biosorption process in water and wastewater treatment: a critical review, Bioresource technology, 160, 57-66.

Anayurt R.A., Sari A. and Tuzen M. (2009), Equilibrium, thermodynamic and kinetic studies on biosorption of $\mathrm{Pb}$ (II) and Cd (II) from aqueous solution by macrofungus (Lactarius scrobiculatus) biomass, Chemical Engineering Journal, 151, 255-261.

Bajpai S.K. and Rohit V.K. (2007), Cation exchanger sawdust (CESD) as an effective sorbent for removal of $\mathrm{Cu}$ (II) from aqueous solution, Electronic Journal of Environmental, Agricultural and Food Chemistry, 6, 2053-2065.

Bhattacharyya K.G. and Sharma A. (2005), Kinetics and thermodynamics of methylene blue adsorption on Neem (Azadirachta indica) leaf powder, Dyes and Pigments, 65, 5159.

Bhattacharyya K.G. and Sharma A. (2005), Kinetics and thermodynamics of methylene blue adsorption on Neem (Azadirachta indica) leaf powder, Dyes and Pigments, 65, 5159.

Bhatti H.N., Akhtar N. and Saleem N. (2012), Adsorptive removal of methylene blue by low-cost Citrus sinensis Bagasse: equilibrium, kinetic and thermodynamic characterization, Arabian Journal for Science and Engineering, 37, 9-18.

Cengiz S., Tanrikulu F. and Aksu S. (2012), An alternative source of adsorbent for the removal of dyes from textile waters: Posidonia oceanica (L.), Chemical Engineering Journal, 189190, 32-40.

Chakraborty S., Chowdhury S. and Das Saha, P (2011), Adsorption of Crystal Violet from aqueous solution onto $\mathrm{NaOH}$-modified rice husk, Carbohydrate Polymers, 86, 1533-1541.

Chen L., Ramadan A., Lü L., Shao W., Luo F. and Chen J. (2011), Biosorption of Methylene Blue from Aqueous Solution Using Lawny Grass Modified with Citric Acid, Journal of Chemical \& Engineering Data, 56, 3392-3399.

Chidambaram T., Oren Y., Noel M. and M. (2015), Fouling of nanofiltration membranes by dyes during brine recovery from textile dye bath wastewater, Chemical Engineering Journal, 262, 156-168.

Chubar N., Carvalho J.R. and M. Joana Neiva Correia M.J.N. (2004), Cork biomass as biosorbent for $\mathrm{Cu}$ (II), Zn (II) and Ni (II), Colloids and Surfaces A: Physicochemistry Engineering Aspects, 230, 57-65.

Deng H., Lu J., Li G. Zhanga G. and Wang X. (2011), Adsorption of methylene blue on adsorbent materials produced from cotton stalk Hui, Chemical Engineering Journal, 172, 326-334.

Doğan M., Ozdemir Y. and Alkan M. (2007), Adsorption kinetics and mechanism of cationic methyl violet and methylene blue dyes onto sepiolite, Dyes and Pigments, 75, 701-713.

Duta A. and Visa M. (2015), Simultaneous removal of two industrial dyes by adsorption and photocatalysis on a fly-ash$\mathrm{TiO}_{2}$ composite, Journal of Photochemistry and Photobiology A: Chemistry. 306, 21-30.

Elemen S., Kumbasar E.P.A and Yapar S. (2012). Modeling the adsorption of textile dye on organoclay using an artificial neural network, Dyes and Pigment, 95, 102-111.

Ferrero F. (2007), Dye removal by low cost adsorbents: hazelnut shells in comparison with wood sawdust, Journal of Hazard Materials, 142, 144-152.
Freundlich H. (1906), Adsorption in solution, Physical Chemistry Society, 40, 1361-1368.

Greluk M. and Hubicki Z. (2013), Effect of basicity of anion exchangers and number and positions of sulfonic groups of acid dyes on dyes adsorption on macroporous anion exchangers with styrenic polymer matrix, Chemical Engineering Journal, 215-216, 731-739.

Hameed B.H. (2008), Equilibrium and kinetic studies of methyl violet sorption by agricultural waste, Journal of Hazard Materials, 154, 204-212.

Ho Y.S. and McKay G.(1999), Pseudo-second-order model for sorption processes, Process Biochemistry, 34, 451-465.

Jaycock M.J. and Parfitt G.D. (1981), Chemistry of Interfaces, Ellis Horwood Ltd., Onichester,

Kanagaraj J., Senthilvelan T. and Panda R.C. (2015), Degradation of azo dyes by laccase: Biological method to reduce pollution load in dye wastewater. Clean Technologies and Environmental Policy, 17, 1443-1456.

Kanawade S.M. and Gaikwad R.W. (2011), Removal of Dyes from Dye Effluent by Using Sugarcane Bagasse Ash as an Adsorbent, International Journal Chemical Engineering and Applications, 2, 203-206.

Krika F. and Benlahbib O.F (2015), Removal of methyl orange from aqueous solution via adsorption on cork as a natural and lowcoast adsorbent: equilibrium, kinetic and thermodynamic study of removal process, Desalination and Water Treatment, 53, 3711-3723.

Krika F., Azzouz N. and Ncibi M.C. (2016), Adsorptive removal of cadmium from aqueous solution by cork biomass: Equilibrium, dynamic and thermodynamic studies, Arabian Journal of Chemistry, 9, 1077-1083.

Lagergren S. (1898), About the theory of so-called adsorption of soluble substances, Kungliga Svenska Vetenskapsakademiens Handlingar,, 24, 1-39.

Langmuir (1918), The adsorption of gases on plane surfaces of glass, mica and platinum, Journal of the American Chemical Society, 40, 1361-1368.

Liang S., Guo X., Feng N. and Tian Q. (2010), Isotherms, kinetics and thermodynamic studies of adsorption of $\mathrm{Cu}^{2+}$ from aqueous solutions by $\mathrm{Mg}^{2+} / \mathrm{K}^{+}$type orange peel adsorbent, Journal of Hazardous Materials, 174, 756-762.

Lu P.J., Lin H.C., Yu W.T. and Chern J.M. (2011), Chemical regeneration of activated carbon used for dye adsorption, Journal of the Taiwan Institute of Chemical Engineers, 42, 305-311.

Ncibi M.C., Ben Hamissa A.M., Fathallah A., Kortas M.H., Baklouti T., Mahjoub B. and Seffen M. (2009), Biosorptive uptake of methylene blue using Mediterranean green alga Enteromorpha spp, Journal of Hazardous Materials, 170, 1050-1055.

Nguyen T.A.H., Ngo H.H., Guo W.S., Zhang J., Liang S., Lee D.J. and Nguyen P.D. (2014), modification of agricultural waste byproducts for enhanced phosphate removal and recovery: potential and obstacles, Bioresource technology, 169, 750762.

Oliveira L.S., Franca A.S., Alves T.M. and Rocha S.D.F. (2008), Evaluation of untreated coffee husks as potential biosorbents for treatment of dye contaminated waters. Journal of Hazard Materials, 155, 507-512.

Que W., Jiang L., Wang C., Liu Y., Zeng Z., Ning Q., Liu S., Zhang P. and Liu S. (2018), Influence of sodium dodecyl sulfate coating 
on adsorption of methylene blue by biochar from aqueous solution, Journal of environmental sciences, 70, 166-174.

Rehman M.S.U., Kim I. and Han J.I. (2012), Adsorption of methylene blue dye from aqueous solution by sugar extracted spent rice biomass, Carbohydrate Polymers, 90,1314-1322.

Romero-Gonzalez M.E., Williams C.J. and Gardiner P.H.E. (2001), Study of the mechanisms of cadmium biosorption by dealginated seaweed waste, Environmental Science and Technology, 35, 3025-3030.

Safa Y. and Bhatti H.N. (2011), Biosorption of Direct Red-31 and Direct Orange- 26 dyes by rice husk: Application of factorial design analysis. Chemical Engineering Research and Design, 89, 2566-2574.

Sharma Y.C. and Upadhyay S.N. (2009), Removal of a cationic dye from wastewaters by adsorption on activated carbon developed from coconut coir, Energy and Fuels, 23, 29832988.

Singh S., Srivastava V.C. and Mall I.D. (2013c), Multistep Optimization and Residue Disposal Study for Electrochemical Treatment of Textile Wastewater Using Aluminum Electrode, International Journal of Chemical Reactor Engineering, 11, 116.

Slimani R., Ouahabi I., Abidi F., El Haddad M., Regti A., Laamari M.R., El Antri S. and Lazar S. (2014), Calcined eggshells as a new biosorbent to remove basic dye from aqueous solution: Thermodynamics, kinetics, isotherms and error analysis, Journal of the Taiwan Institute of Chemical Engineers, 45, 1578-1587.

Sparks D.L. (1999), Soil Physical Chemistry, second ed., CRC Press, USA.

Turgay O., Ersoz G., Atalay S., Forss J. and Welander U. (2011), The treatment of azo dyes found in textile industry wastewater by anaerobic biological method and chemical oxidation, Separation and Purification Technology, 79, 26-33.

Vaghetti J.C.P., Lima E.C., Royer B., Brasil J.L., da Cunha B.M., Simon N.M., Cardoso N.F. and Norena C.P.Z. (2008), Application of Brazilian-pine fruit coat as a biosorbent to removal of $\mathrm{Cr}(\mathrm{VI})$ from aqueous solution: Kinetics and equilibrium study, Biochemical Engineering Journal, 42, 6776.

Verma A.K., Dash R.R. and Bhunia P (2012), A review on chemical coagulation/flocculation technologies for removal of colour from textile wastewaters, Journal of Environmental Management, 93, 154-168.

Wang Y., Zhang Y., Li S. Zhong W. And Wei W. (2018), Enhanced methylene blue adsorption onto activated reed-derived biochar by tannic acid, Journal of Molecular Liquids, 268, 658666.

Weber W.J. and Morris J.C.(1963), Kinetics of adsorption carbon from solutions, Journal Sanitary Engineering Division Proceedings. American Society of Civil Engineers, 89, 31-60, 1963. 